\title{
The COVID-19-crisis and the information polity: An overview of responses and discussions in twenty-one countries from six continents
}

\author{
Albert Meijer ${ }^{\mathrm{a}}$ and C. William R. Webster ${ }^{\mathrm{b}}$ \\ ${ }^{a}$ Utrecht University, Utrecht, The Netherlands \\ ${ }^{\mathrm{b}}$ University of Stirling, Scotland, UK
}

\section{Contributing Authors}

Frank Bannister, Colin J. Bennett, Kaiping Chen, Heungsuk Choi, J. Ignacio Criado, Maria Alexandra Cunha, Mehmet Akif Demircioglu, Mila Gasco-Hernandez, Paul Henman, Douglas Kimemia, Veiko Lember, Karl Löfgren, Luis F. Luna-Reyes, Albert Meijer, Ines Mergel, David Murakami Wood, Giorgia Nesti, Erico Przeybilovicz, Aarthi Raghavan, Ola Svenonius, Rosamunde van Brakel, William Webster, Mete Yildiz.

\begin{abstract}
Governments around the world are utilizing data and information systems to manage the COVID-19-crisis. To obtain an overview of all these efforts, this global report presents the expert reports of 21 countries regarding the relation between the COVID-19-crisis and the information polity. A comparative analysis of these reports highlights that governments focus on strengthening six functions: management of information for crisis management, publishing public information for citizens, providing digital services to citizens, monitoring citizens in public space, facilitating information exchange between citizens and developing innovative responses to COVID-19. The comparative overview of information responses to the COVID-19-crisis shows that these responses cannot only be studied from a rational perspective on government information strategies but need to be studied as political and symbolic interventions.
\end{abstract}

Keywords: COVID-19, information polity, corona app, corona dashboard

\section{Introduction}

The COVID-19 Pandemic has diffused globally at an alarming rate and has forced countries to undertake a broad range of unprecedented interventions in order to protect their citizens from this disease. The

\footnotetext{
${ }^{*}$ Corresponding author: Albert Meijer, Utrecht University School of Governance, Bijlhouwerstraat 6, 3511 ZC, Utrecht, The Netherlands. E-mail: a.j.meijer@uu.nl.
} 
lockdowns that we have seen in many countries are the clearest manifestation of the extreme measures that have been taken to stop the spread of the disease. Health experts have played a key role in the development of policies, but there has also been a strong emphasis on information management as a key element in effective crisis management (Ienca \& Vayena, 2020). Governments around the world are utilizing data and information systems to provide crucial insights about the spread of the virus and the management of this pandemic.

The media has presented a range of analyses and insights about the technological facilities developed to help manage the pandemic, including the provision of 'corona dashboards' and mobile phone contract tracing apps. Optimistic analyses highlight the key role these information systems play in detecting new occurrences of the disease and argue that this type of information provides the basis for chirurgical interventions (see for example the paper on the 'hammer and the dance': Pueyo, 2020). Critical analyses of these solutions highlight the risks of creating a surveillance state and the large-scale invasion of personal privacy (see for example Harari's (2020) critical analysis of 'under-the-skin' surveillance). Whilst there is an interesting debate about the pros and cons of these solutions, there is currently no systematic overview of how countries around the world are using information technologies in their crisis management policies. For this reason, we have decided to bring together researchers from 21 countries and all continents to provide a broad overview of the relationship between the COVID-19-crisis and the information polity. We have asked these authors to present a systematic overview of the relation between the COVID-19-crisis and the information polity in their country on the basis of the following questions:

- How and when did the corona crisis manifest itself in your country?

- What was the role of information technology in findings ways to deal with the COVID-19-crisis?

- What ethical and sensitive issue were identified in this role?

- What was the political and public debate about using new technology in way?

- What was the outcome of these debates and the solution(s) eventually selected?

- Is there any published information about the success of the chosen solution(s)?

- Are there any concrete indications of negative effects of the chosen solution(s)?

This global report presents country reports of 21 countries and an analysis of the patterns discernable in these findings. The country reports have been drafted by national experts on their reading of the media reports and of formal (government, NGO and academic) publications. The reports are not based on systematic academic research, but on an explorative analysis of available materials and therefore further research is needed to validate and extend these findings. At the same time, in view of the urgent need for debates about issues surrounding the pandemic, we deemed it necessary to generate knowledge about informational and technological responses in different countries, in order to enable a more informed public and political debate on these issues and to help to guide and focus future academic research.

An overview of these countries in terms of total number of cases of COVID-19, total number of deaths, total number of tests and cases, deaths and tests per million inhabitants is presented in Table 1 below (ordered on the basis of the total number of cases). The table shows a huge variation in the human cost of the pandemic in different countries. Explanations for this variation are due in part to differences in national policy and strategy, a situation which cannot be divorced from the role and functioning of the information polity, or more accurately in this case national information polities.

It is not possible to provide a detailed analysis for each country discussed here. Rather, the approach taken is to provide a broad overview of events in each country in order to draw out comparative international themes, similarities and differences. This general overview is currently absent from existing published materials and as such represents a new contribution to our understanding of technological 
Table 1

Overview of countries in the multi-country report

\begin{tabular}{lllllllll}
\hline $\begin{array}{c}\text { Worldwide } \\
\text { ranking } \\
\text { (total } \\
\text { cases) }\end{array}$ & Country & $\begin{array}{c}\text { Total } \\
\text { cases }\end{array}$ & $\begin{array}{c}\text { Cases/ } \\
1 \text { M pop }\end{array}$ & $\begin{array}{c}\text { Total } \\
\text { deaths }\end{array}$ & $\begin{array}{c}\text { Deaths/ } \\
1 \mathrm{M} \text { pop }\end{array}$ & $\begin{array}{c}\text { Total } \\
\text { tests }\end{array}$ & $\begin{array}{c}\text { Tests/ } \\
\text { 1M pop }\end{array}$ & Population \\
\hline 1 & USA & $3,041,035$ & 9,186 & 132,981 & 402 & $38,218,637$ & 115,452 & $331,034,037$ \\
2 & Brazil & $1,626,071$ & 7,649 & 65,556 & 308 & $4,316,284$ & 20,304 & $212,582,910$ \\
6 & Spain & 298,869 & 6,392 & 28,388 & 607 & $5,734,599$ & 122,652 & $46,755,120$ \\
8 & UK & 285,768 & 4,209 & 44,236 & 652 & $10,651,308$ & 156,886 & $67,891,886$ \\
9 & Mexico & 261,750 & 2,013 & 31,119 & 241 & 641,142 & 4,972 & $128,951,496$ \\
11 & Italy & 241,819 & 3,997 & 34,869 & 578 & $5,962,744$ & 98,626 & $60,458,424$ \\
14 & Turkey & 206,844 & 2,452 & 5,241 & 62 & $3,682,673$ & 43,659 & $84,351,507$ \\
16 & Germany & 198,064 & 2,364 & 9,092 & 109 & $5,873,563$ & 70,1 & $83,788,628$ \\
20 & Canada & 105,935 & 2,806 & 8,693 & 230 & $2,975,711$ & 78,833 & $37,747,023$ \\
22 & China & 83,565 & 58 & 4,634 & 3 & $90,410,000$ & 62,814 & $1,439,323,776$ \\
25 & Sweden & 73,061 & 7,234 & 5,433 & 538 & 519,113 & 51,396 & $10,100,272$ \\
30 & Belgium & 62,058 & 5,354 & 9,774 & 843 & $1,284,605$ & 110,833 & $11,590,476$ \\
32 & Netherlands & 50,657 & 2,956 & 6,128 & 358 & 616,376 & 35,971 & $17,135,554$ \\
38 & Singapore & 44,983 & 7,688 & 26 & 4 & 757,746 & 129,506 & $5,851,040$ \\
51 & Ireland & 25,531 & 5,17 & 1,741 & 353 & 467,852 & 94,735 & $4,938,531$ \\
56 & Japan & 19,775 & 156 & 977 & 8 & 499,898 & 3,953 & $126,468,508$ \\
64 & S. Korea & 13,181 & 257 & 285 & 6 & $1,346,194$ & 26,257 & $51,270,007$ \\
71 & Australia & 8,755 & 343 & 106 & 4 & $2,800,030$ & 109,789 & $25,503,813$ \\
74 & Kenya & 8,067 & 150 & 164 & 3 & 191,394 & 3,559 & $53,780,608$ \\
111 & Estonia & 1,994 & 1,503 & 69 & 52 & 109,338 & 82,423 & $1,326,552$ \\
122 & New Zealand & 1,536 & 307 & 22 & 4 & 416,924 & 83,35 & $5,002,100$ \\
\hline
\end{tabular}

Source: https://www.worldometers.info/coronavirus/, 7 July 2020.

responses to the global COVID-19 pandemic. The country reports presented here are analyzed comparatively to exploratively identify general patterns in information polity responses to COVID-19. The country reports are presented alphabetically in Section 2 of the report and are followed in Section 3 by a more detailed comparative analysis. Our ambition here, is to contribute to societal and academic debates about the use of information technologies for dealing with the COVID-19-crisis.

\section{Country reports}

\subsection{Australia}

Paul Henman, University of Queensland, p.henman@uq.edu.au

Australia is a federated state of six states and two territories. States have primary responsibility for public health emergency and infection disease management, while the national government has responsibility to infection control across national borders. Australia has managed COVID-19 infections remarkably well, with borders blocked for Chinese arrivals from 12 February 2020, and all arrivals from 20 March, with several internal state borders closed shortly thereafter. As of 1 July, Australia recorded 7834 infections and 104 deaths (that is, 307 and 4 per million people respectively), with over 60 percent of cases imported from overseas.

Information technologies for mapping infections and modelling of infection spread has been central to the public governance of COVID-19 in Australia. However, such technologies have been utilised in a context of criticism over government secrecy and unaccountability. From March 2020, a new National Cabinet, constituted by the leaders of all state, territory and federal governments, relied on micro- 
simulation modelling to develop lockdown policies and procedures, but the governments were reluctant and slow in releasing their modelling for comparison with those of independent researchers.

The Australian government also developed two smart phones apps for managing the COVID-19 pandemic. Coronavirus Australia was released on 29 March by the federal Department of Health to provide access to official information, health information and updates, but it had little visibility and was simply an app version of the government's informational website. These national level data were replicated at a state level on state government websites. Providing updated statistics, infographics and trend data, they had some rudimentary dashboard like characteristics, although they were not described as dashboards.

In contrast, the COVIDSafe developed by the Australian government's Digital Transformation Agency to support contact tracing of infected persons received considerable attention. Using the BlueTrace open-source application developed by the Singaporean government for its TraceTogether app, COVIDSafe was released on 26 April 2020. Data is stored on a single centralised database hosted by Amazon cloud services, and accessed by state public health authorities. While there was initial strong take-up, its publication generated considerable public debate about privacy and the tracking of users. Several 'mistakes' by the national government reinforced privacy concerns:, at its launch the source code was promised and then delayed until 8 May; there were no clear legal privacy protections in place; the government initially failed to rule out making the app mandatory; the government failed to acknowledge significant technical limitations of COVIDSafe's operation on Apple's IOS systems; and, the levels of testing were not disclosed. The Australian government also oversold COVIDSafe, with the Prime Minister likening it to wearing sunscreen to protect against sun burn and subsequent skin cancer. This resulted in some people viewing the app as a protective panacea to COVID-19, and some organisations declaring that people without the app would be denied entry. The Prime Minister also sought to compel people to use the app by stating that it was necessary before lifting restrictions could be considered.

Several factors diminished the app-related controversies. Specific legislation to clarify and strengthen privacy protections relating to the COVIDSafe app were instituted on 16 May. Downloads of the app stabilised at just over six million by the end of May. Most significantly, due to the significant success in controlling infections (typically less than 10 new infections a day during June, and only one death from 23 May to end June), restrictions began lifting mid-May. Yet, as of late June, COVIDSafe had yet to be used to successfully identify contacts to an infected person, eliciting the question of whether the app created as a 'shiny' technical fix to a social problem?

\subsection{Belgium}

Rosamunde van Brakel, Vrije Universiteit Brussel, Rosamunde.Van.Brakel@vub.be

Belgium was hit relatively hard by the COVID-19 pandemic, with a high number of deaths. The virus was confirmed to have spread to Belgium on 4 February 2020. It became significantly worse after people returned from spring holiday at the beginning of March. The National Security Council ordered a 'lockdown light' from Friday 13 March at midnight onwards which included the closure of schools, discos, cafes and restaurants, non-essential shops and companies and the cancellation of all public gatherings and the message that people need to work from home and leave the house as little as possible. Starting early May the lockdown measures were removed in different phases. Updates about number of deaths, hospital admissions, beds filled in intensive care and new cases were communicated via the main media outlets every day. Early in the outbreak Belgium did not have much test capacity but from April onwards the test capacity expanded significantly with first 10.000 to 19.900 tests a day at the beginning of May. 
At the end of March, the Minister of Health and the Minister of Digital Agenda and Privacy launched a taskforce 'Data \& Technology against Corona'. Members of the taskforce included representatives of the Ministry of Health, Sciensano, the e-health platform and the Belgian Data Protection Authority. The goal of the taskforce was to oversee and coordinate all mhealth initiatives. The possibility of developing a contact tracing app was explored but at the end it was concluded that this was not a decision for the Federal government to make but should be taken by the regional Flemish, Walloon and Brussels governments. The general vision of experts involved in the taskforce but also in the exit-committee is that the app should complement human contact tracing. The work of the taskforce was not transparent, and several open letters signed by academics and opinion pieces were published raising human rights and privacy issues about a possible app. Two surveys were conducted in Flanders asking about public acceptance of a possible contact-tracing-app and half of respondents indicated they would not install it. Human contact tracing started in June 2020 and an ICT platform and database were set up by Sciensano to support the work. Since it started the contact tracing has encountered many technical issues. Also, much criticism came from civil society and academia about the legal framework accompanying the tracing that it does not respect human rights.

In June 2020 an inter-federal interdisciplinary working group was set up by Professor Bart Preneel from the University of Leuven who is one of the leading partners in the Decentralized Privacy-Preserving Proximity Tracing (DP-3T) app initiative. The protocol proposed by this group uses Bluetooth Low Energy to track and log encounters with other users. It is considered the most privacy-friendly app solution as no data is stored centrally by the government. The goal of the working group is to work out policy measures for the Belgian version of the app. A cooperation agreement between the regional governments was finalized in a couple of weeks, which usually would take 2 years to make this possible. It is expected that the app is operational in September 2020.

Apart from the app surveillance technologies have been used by the government to enforce lockdown rules. Speaking drones have been used in Brussels to spread messages about social distancing, drones with heat cameras have been used to identify people illegally staying in their second homes and caravans at the coast. Further, telecom data and smart video surveillance are used to track movements of people and to monitor how busy the shopping streets and the beach get.

\subsection{Brazil}

\section{Maria Alexandra Cunha, Fundação Getulio Vargas, alexandra.cunha@fgv.br}

Erico Przeybilovicz, Fundação Getulio Vargas, erico.prz@fgv.br

In January 2020, Brazil was aligned with WHO and closely followed the global crisis of COVID-19. On the $26^{\text {th }}$ the first case was confirmed, with the first death occurring on March $17^{\text {th }}$. After March $24^{\text {th }}$, the national policy started to diverge from WHO recommendations. President Bolsonaro gave a disastrous televised speech advocating a return to normality and the end of social distancing, blaming the media for spreading fear. Subsequently, the policies of the federal, state and municipal governments began to diverge from soft measures like social distancing to lockdowns. The Minister of Health was dismissed on April $16^{\text {th }}$ and a new Minister took over, only to resign 28 days later. An Army General took office as interim Minister, a supposedly temporary arrangement that lasts to this day. On June $24^{\text {th }}$, Brazil counted 1.188 million confirmed cases, 53,830 deaths, high levels of underreporting, and an unknown number of tests (estimated at 2.3 tests for each positive case). With no easing of the crisis in sight, federal, state, and municipal governments are still adopting measures with different desired policy intentions.

The federal government established three fronts of action: (1) strengthening the epidemiological monitoring systems; (2) preparing intensive care units (ICUs); and (3) enabling remote primary healthcare. IT 
supported these fronts by: (a) a flu monitoring system; (b) updating the registration of 110 million people on the Health System eSUS database; (c) implementing Telesus, a robocall system for classification, diagnosis, tracking, and registration of epidemiological risk that was abandoned after the dismissal of the Minister following more than 23 million effective calls; (d) telemedicine focused primarily on assisting health professionals; (e) the Coronavirus-App for information about the disease; (f) the coronavirusdashboard; (g) a citizen service channel through WhatsApp; and, (h) another dashboard to track resources for the pandemic. On June $5^{\text {th }}$, the interim Minister changed the coronavirus-dashboard to omit information on total cases and deaths. This provoked a strong reaction and the Supreme Court decided that the government must disclose the complete data.

During the COVID-19 crisis, media, civil society, universities, representative institutions, states, and cities have used open data to launch COVID-19 dashboards reporting the spread of the disease. Small municipalities have been using social media to disseminate information and guidance. A few cities have also used drones to monitor agglomerations, while the telecom companies have established a dashboard to track movement in the towns available only to municipal governments. Contact tracing applications have been launched by startups without much support or public engagement. Another action supported by IT is the emergency aid, a benefit of three payments of BRL $\$ 600$ per month (less than E\$100) granted by the federal government to informal workers, micro-entrepreneurs, the self-employed, and the unemployed. More than 60 million people have received the benefit. However, the benefit request can be made only through the public bank's website or through an app, cruelly exposing the digital divide whereby 50 million people do not have internet access. Most of these individuals are eligible for the benefit and have experienced huge difficulties in accessing it.

Public debate around the role of IT has concentrated on the digital divide, transparency, and privacy. The exclusion debate has focused on the inadequacy of a digital-only channel such as the Emergency Aid App, while transparency refers to the coronavirus-dashboard hiding information on deaths and cases. Privacy and surveillance issues have emerged from the use of citizen registration and monitoring systems, drones, and mobile data. At the same time, technology has allowed people to react, to produce information, and to launch "parallel" coronavirus-dashboards based on open data provided by subnational governments, thus maintaining transparency. Social media has worked well in small towns as a way of disseminating information to the population.

The political context has dramatically influenced the use of technology during the COVID-19 crisis in Brazil. What started as a public health crisis has evolved into a broader political and institutional crisis, consequently drowning out the ethical debate on the use of IT.

\subsection{Canada}

Colin J. Bennett, University of Victoria, BC, cjb@uvic.ca

As of mid-June, Canada had experienced around 100,000 confirmed cases of Covid-19 and around 8,000 deaths. Around 2 million Canadians have so far been tested. Those figures obscure a significant variation across the country. The vast majority of cases have occurred in Ontario and Quebec, and particularly in the Toronto and Montreal metropolitan areas. Other provinces, such as British Columbia, have fared relatively well. Canada's proximity to the United States, the country with the highest number of cases and deaths makes Canada extremely vulnerable as a result of cross-border traffic. Many of the early cases in Quebec, for instance, were attributed to students returning from Spring Break in Florida, as well as to close ties to New York.

Health care services are delivered through provincial governments in Canada, and so we have seen different provincial approaches to quarantining and social-distancing, testing criteria, and modes of public 
health communication. Health Canada, and the respective public health agencies in each province operate websites with dashboards on confirmed case counts and deaths by age and gender, testing rates, outbreaks and advice about preventive measures. Health Canada and Statistics Canada have been trying to ensure that the statistical reporting is consistent across the country.

On contact-tracing, the federal government also initiated a recruitment drive for specialized contacttracing volunteers to assist the provinces. It has been more cautious, however, in developing contact-tracing smart phone apps. Prime Minister Trudeau announced on May 22nd that the government would offer a strong recommendation for a particular app, but there was reportedly resistance from some provinces who preferred traditional approaches. Two provinces, Alberta and Newfoundland and Labrador, initially decided to develop their own apps. Neither has been popular. There was also push-back from civil liberties advocates and privacy regulators. The federal, provincial and territorial privacy commissioners issued a joint statement on May 7th, reminding governments that these devices will only be trusted if privacy and security considerations are front and center. The network of Canadian civil liberties organizations also weighed in to warn against overreaching surveillance measures with the potential to endure after the crisis is over, and the emergency powers are cancelled.

Concerned to develop a coherent national approach, the federal government announced on June 18 that a voluntary contact-tracing app would be available in July - first in Ontario and then across the country. Covid Shield has been built using open-source code by the Ontario Digital Service in conjunction with a volunteer team from the Ottawa-based company Shopify. The app uses randomly generated anonymous codes and Bluetooth signals to track proximity and duration of contact. Those who have tested positive will he encouraged to upload their status using a unique code provided by a health care provider. The app will alert those who have been in close proximity to take appropriate action. The app is being promoted as totally anonymous, with no geo-tagging of location, and no centralized storage of the data. Initial feedback from the civil liberties advocates has been positive, although they did not seek the endorsement of the Federal Privacy Commissioner before announcing this decision.

So far, the debate about contact-tracing in Canada, as elsewhere, has been framed as a binary choice between the use of shiny new smart-phone applications, and the laborious and traditional method of interviewing. However, the analysis of third-party transactional records might also play a role in the contact-tracing process: credit card transactions; reservation systems; membership lists; employee records; Barwatch programs; or the non-anonymized data captured from mass transit smart card systems. Canadian public health authorities have a right to demand and receive all such information under the emergency powers in our provincial Public Health Acts, and despite any provisions within provincial privacy laws. The use of third-party records will not identify all possible contacts - but they will identify a lot.

\subsection{China}

\section{Kaiping Chen, University of Wisconsin-Madison, kchen67@wisc.edu}

The COVID-19 pandemic started to explode in Wuhan in January 2020 and spread quickly to other provinces. Many cities across China started lockdown in February. Around the middle March, except for in the Hubei province, the average new daily cases dropped to single digits across China. Cities started to re-open in late March and the rate of infection has been well maintained since then.

One crucial factor that enabled China to achieve a quick control of COVID-19 cases is in its use of information technology. Technology was adopted by all levels of government and was used penetrate deeply into people's lives. The well-known state-led deployment of information technology to monitor COVID-19 was only possible due to cultural and structural institutions in China, without which enforcement via information technology will not be effective. 
The first is China's extensive neighborhood governance system, serving as the backbone for monitoring. E-governance cannot be effectively enforced without complementary governance systems. The major neighborhood governance system in China is the "neighborhood/village committee" which was established in early 1950s. This agency integrates community self-governance and street-level bureaucracy. Take one large community in Shanghai for example, the neighborhood committee staff coordinated with the citizen manager of each apartment building to make sure that each household joined the apartment WeChat group, a place where residents obtain timely information of COVID-19 in the community and the city. The WeChat group is also a place for those who travelled to report where they went and their daily temperature. In hotspot communities, street-level bureaucrats performed "blanket search" to test every individual in the communities where infected people went. In the hotspot city Wuhan, tests were conducted on almost every citizen (i.e., 9.9 million people) in two weeks in May.

The second is China's use of its existing e-governance platforms and apps that citizens are already familiar with. From government websites to government apps, public dashboards for COVID-19 were created from the outset of the outbreak to provide citizens nuanced information about COVID-19, including daily number of new infections and deaths, as well as detailed mobility information regarding where these newly infected individuals had traveled. At the national level, the State Council embedded the new COVID-19 platforms into its existing official WeChat account. Once a user scans the WeChat QR code, they can engage with different platforms, from the latest cases, to COVID-19 services such as purchasing facial masks and mental health hotlines. Citizens can also post questions on the platform to interact with the state body.

Sub-national level governments also embedded COVID-19 platforms into their existing apps, which have been used by many citizens. For instance, in Shanghai, citizens need to show their health QR code when they take public transportation, go to offices, restaurants and even neighborhood supermarkets. The health QR code is adopted from an existing app, "Get All Public Services Done Electronically", that the city government developed for citizens to do over 30 bureaucratic services online such as tax and social welfare. This app was launched in September 2018 and within half a year, there are over 10 million app users (i.e., $40 \%$ of the population). In mid-February, this app created a section where citizens can obtain their health QR code using real names and national IDs. Citizens can also obtain the health QR code from other familiar platforms such as WeChat or Alipay. These apps do not send information to people who have been close to somebody with COVID-19. There is a nation-wide centralized database that integrates various data from citizens. This centralized database is used to determine the status of citizens' health QR code. The health QR code was implemented in over 200 cities as is one of the largest digital monitoring efforts used to track COVID-19. There has been ongoing and extensive discussion between app developers, governments and the academia regarding how to ensure user privacy of these apps. Some citizens and enterprises also raised ethical concerns.

\subsection{Estonia}

\section{Veiko Lember, Tallinn University of Technology,veiko.lember@ttu.ee}

The first COVID-19 case was confirmed in Estonia on February 27, while the government declared the state of emergency on March 12 after which borders and public spaces were gradually shut down, some regions (islands) were sealed off and social distancing regulations were imposed. The first death attributed to COVID-19 was recorded on March 25. As of June 15, the country of 1.3 million inhabitants had lost 69 people to the COVID-19 infection, while altogether 1,974 people out of 96,638 tested have been identified positive. Testing was initially restricted to the most vulnerable groups in society and to the people with explicit symptoms, while more targeted testing, e.g., in elderly care homes and among 
front-line workers was introduced later. In May, there was also two surveys initiated by the government to map the spread of the virus among the population and people without family doctor referrals could start using fee-based testing services of private labs. The lock-down was gradually eased from April 27 onwards, with the emergency situation ceasing on May 17. Still, borders remained partly closed and many organizations, including schools and universities, continued operating on-line. In general, the public accepted the imposed harsh restrictions.

Information technology was used on several fronts to deal with the COVID-19 crisis. The government initially struggled in pooling health data and disseminating accurate information, and as a reaction, many private dashboard initiatives were launched by civil society organizations and universities. Some weeks into the crisis, the government managed to create a central data platform by upgrading the existing health data system. Relatedly, the national health agency also launched its own publicly accessible COVID-19 dashboard. In addition, the government used social campaigns as well as e-mail and mobile phone data available in the centralized population registry to reach out to citizens with crisis announcements. In addition to physically calling to and visiting people, drones and other technologies used by police to enforce various emergency regulations in public spaces. The government also initiated a mobility survey using mobile positioning data in cooperation with telecommunication and other private companies. The health system had to learn almost overnight how to organize online consultations (allegedly ca $75 \%$ of all family doctors consultations during the peak of the crisis), while the transition to distant learning was enabled by the already effective e-school infrastructure, albeit with significant transaction costs for parents, students and teachers.

Typical to the Estonian government, several hackatons with both national and global reach were kicked off. According to the government sources, more than 20 applications including on-line coronavirus questionnaire, COVID-19 chatbots and automatic sick leave letter admission were developed during the crisis. Also, the Estonian government decided to partner with Estonian tech companies to develop a contact tracing application following the decentralized DP-3T protocol and capable of integrating with the system supported by Google and Apple. As of June, the application was still under development and had caused limited public debate.

The COVID-19 crisis also revealed important shortcomings in the government ICT capabilities. The government lacked high-quality and real-time monitoring system to track and predict the spread of the virus. The key central agency responsible for fighting the crisis - the Health Board - publicly admitted that they suffered from limited in-house data and ICT capabilities to react quickly to the emerging situation. Some crucial interoperability issues emerged when, for example, the health and police databases could not exchange data, causing inconveniences for people and unnecessary workload for police. The attempt to use mobile positioning data for mapping the change in population mobility was riddled with data protection debates and culminated in a rather abstract analysis and no clear follow-up plans.

\subsection{Germany}

Ines Mergel, University of Konstanz, ines.mergel@uni-konstanz.de

Germany discovered one of the first corona clusters in Europe in January 2020 at an automotive supplier in Munich. Sixteen people were infected by patient zero - a visiting co-worker from China. The infected workers and their contacts were quickly isolated and contact tracing helped initially to contain the spread. Subsequently however, borders, schools, day cares, Universities and stores closed on March 13, 2020. Air travel stopped, civil servants on the local and state level, as well as all other non-essential workers were sent into make-shift home offices. The official lock-down measures lasted until June 15, 2020 with intermediary release of individual regulations or localized restrictions in hotspots. Criticism focused 
on limitations to the freedom to travel within the otherwise borderless European Union. Politically, the Corona crisis has surprisingly unified the political parties leading up to and during the lockdown. The success of the invasive measures is mainly attributed to Chancellor Merkel's calm and decisive speeches that appealed to citizen's sense of community and highlighted the severity of the virus. With preexisting high trust in government operations in general, the decisions were largely supported.

IT played an important role during the lockdown and changed the way that public services are delivered today. Germany, usually listed mid-field in e-Government rankings, has chosen a pragmatic digitization approach during the lockdown: Existing long-term digitalization budgets were shifted to allow for ad hoc digitalization of immediate financial assistance programs for the self-employed, artists, etc. The political will to digitize the work of public administrations to keep the country open, has pushed civil servants who usually delay decisions and focus on coordination and control issues to act, convinced by the urgency of the situation.

Policy making has been data-driven: decision were based on insights from public health experts and virologists. Public health data was collected on a daily basis, testing capacity increased to over $1 \mathrm{~m}$ tests per week, personnel was shifted to public health agencies to increase contact tracing, and the publicly available Corona dashboard served as the decision-making basis for daily political decision making. It displays officially reported new infections per day, cumulative data, and feeds into the daily situation reports which include R0 measures published by the Robert Koch Institute, Germany's central public health agency. The nation-wide $€ 20 \mathrm{~m}$ Corona Warn App was designed by SAP and was released on June 15, with an initial $12.5 \mathrm{~m}$ downloads. It was designed with input from civil society after criticism on surveillance, central data collection, storage on the Open Telekom Cloud (OTC), unclear responsibilities and competencies in the reuse of the data. The software code is available on Github for continuous improvements from civil society, and traces are not transferred to the government, but are saved locally.

Law makers and civil society discussed the obligation to use the app at length and have now decided an opt-in approach by appealing to the "Together against Corona" mantra. The debate and slogans propagated by politicians appeal to German citizens' sense of community - to see their contributions of using the app as a consensus of the whole society, but especially to protect those who are most risk from the disease. This emphasis on inclusion is reminiscent of the decisions made during the 2015 refugee crisis. The relative transparent decision making around the Corona app is also a response to other information technologies that were deployed without consultation in an ad hoc fashion.

The German government has initiated the \#WirVsVirus hackathon: In 48 hours a record of 28,361 people worked together on over 1,300 technological solutions for societal and governmental virus-related problems and partnered with civil society to implement over 130 of the submitted solutions. Working in agile sprints, civil servants collaborate with the hackers to scale up their solutions and to ensure they could be implemented.

\subsection{Italy}

\section{Giorgia Nesti, University of Padova, giorgia.nesti@unipd.it}

Italy was the first European Country affected by Covid-19. On January $31^{\text {st }}$ two tourists were hospitalized in Rome while the first hotbeds of contagion emerged in Lombardy and in the Veneto Region where, on February $21^{\text {st }}$, the first official deaths were reported. After that, twelve municipalities were lockeddown and between February $23^{\text {rd }}$ and March, the Italian Premier Giuseppe Conte officially enforced Phase 1 to control the pandemic nationally. During this period all borders were closed, movements within and across regions were prohibited, schools, Universities and commercial and touristic activities were suspended, while social distancing and the use of masks were introduced. On May $16^{\text {th }}$ the Government 
launched the transitionary Phase 2 with a gradual reopening of all activities. Since February, 241,819 confirmed cases of Covid-19 have been reported in Italy, 195,106 people have recovered and there have been 34,869 deaths, $95 \%$ of which have been aged between 60 and 90 .

Since February the Italian Government has launched several digital technology initiatives to cope with the emergency. In order to inform citizens about the spread of the virus, the Civil Protection department created a COVID-19 Dashboard modelled on the CSSE at Johns Hopkins University and an open data repository on GitHub. The Ministry for Technological Innovation and Digitalization (MID) and the Italian Agency for Digitalization created the online platform Digital Solidarity where firms and civil society associations make freely available digital services for smart working, e-learning, and e-reading. They launched the call for action 'Innovation for Italy' inviting firms, universities, foundations, and non-profit organizations to propose innovative services, products, or technologies to prevent, diagnose and control the pandemic. A similar approach was also adopted within the regions, particularly in Veneto where a call for innovative digital ideas and projects to manage the emergency is still open. The MID accelerated the process of digitalization of public administration and created a Task Force for Covid-19 Emergency, made of 74 experts who assess and propose data-driven solutions to fight the virus. The Government also invested 1.546 million Euros in ultra-broadband infrastructures and funded the digitalization of the public sector with 50 million Euros. Finally, on April 16th, the Government signed a contract with the private firm Bending Spoon and the Medical Center Sant'Agostino to develop an app for contact tracing called Immuni.

The launch of the app initiated a lively debate in the Italian Parliament, within civil society, and in the media. Several concerns were expressed, about the risk that the weak public agencies' information systems could be hacked, and about the violation of citizen's privacy. To cope with these security issues the Government assigned Immuni's data management to the public company Sogei, that uses a centralized server and public infrastructures located within Italian national borders while the source code is released under a GNU Affero General Public License. The system is based on Bluetooth Low Energy and does not use geolocation data so it can trace whether a contact with an infected person took place, how long it lasted, and it can estimate the distance that separated the two users, but it can't trace where the contact took place, nor who was involved. After a MID's parliamentary audition and the authorization issued by the Italian Data Protection Authority, the Italian Council of Ministries officially approved Immuni on June $1^{\text {st }}$ and the app has been available from June $15^{\text {th }}$. To be effective Immuni is required to be downloaded at least by 20 milion smarthphone users, and to nudge those who received a notification of exposure to COVID-19 to voluntarily self-isolate.

\subsection{Ireland}

\section{Frank Bannister, Trinity College Dublin, FBNNISTR@tcd.ie}

The first case of the virus found in Ireland was recorded on February $29^{\text {th }}$. It was diagnosed in a teenager who had just returned from a school trip to northern Italy. The virus's arrival was not unexpected. For a number of weeks the country had been scrambling to prepare. Ireland faced a number of problems including a low number of Intensive Care Unit (ICU) beds, a limited number of available public hospital beds, limited facilities to test for the virus and a severe shortage of personal protective equipment (PPE). To complicate matters, a general election in February resulted in a hung parliament. Constitutionally, a government, despite having been defeated in the election, remains in office until a new government is sworn in. It has performed surprisingly well. The strategy adopted was to flatten the curve. This involved an immediate lockdown. The government took over (for a fee) the country's private hospitals, thus adding around 2,000 more beds. It ramped-up the number of ICU beds. An all-out effort was initiated to speed up testing turnaround and capacity and a large consignment of PPE was sourced from China. 
Information and ICT have played key roles in this. The government immediately adopted a policy of full transparency, thus establishing a high level of trust in its data. Updates are published daily on the government's website, www.gov.ie, that include, inter alia, the latest statistics (deaths, cases, number of tests, etc.), charts, maps and minutes of the pandemic management group. A system was rapidly developed for General Practitioners that enabled them to schedule tests for patients who telephoned in reporting Covid-19 type symptoms. The patient receives an appointment (usually within 24 hours) at the nearest testing centre, again on their mobile. As soon as they are available, the test results are sent electronically to both patient and GP. The government has set up 30 testing centres using every location it could find (including a warship docked in Dublin port).

Amongst the more surprising consequences of the pandemic is that issues that had been fought over for years were suddenly resolved. Electronic prescribing went nationwide almost overnight after years of argument between vested interests. Tele-consultations with doctors have become common. Less impressive was the development of a mobile app for contact tracing. Initially promised for March, it was finally delivered in early July. How effective it will be remains to be seen; some experts and academics have pointed out various problems with the concept. The App is based on the German model and was developed by a government team in conjunction with Apple and Google. It uses Bluetooth technology to measure when two mobiles have been within two metres for more than 15 minutes (without revealing the identity of the positive person). The App notifies users if they have been in close contact with an infected person. No data is centrally stored.

To date, these actions have been effective. Hospitals and ICU beds have not been swamped The number of people in both is now falling as are the number of new cases and the number of deaths. The phasing out of lockdown was accelerated by the government in early June. Meanwhile, several Irish scientists are arguing for a New Zealand type strategy of crushing the virus, though this would require a larger scale testing and tracking system and widespread uptake of the App. Ireland is an island, so such a proposition is feasible, though what we do about our large tourism industry is unclear. For now, everybody continues to pay close attention to the numbers.

\subsection{Japan}

\section{David Murakami Wood, Queen’s University,dmw@queensu.ca}

Given that Japan is advancing a highly future-oriented series of policies towards "Society 5.0", it may be surprising that its response to COVID-19 has often been low-tech. Data-gathering and collation has often been carried out with pencils, paper, the fax machine and inked stamps (hanko). This bureaucratictechnological path-dependency has resulted in some mistakes in data-transfer, but also in $80 \%$ of officeworkers having no choice but to go into work physically despite government advice not to, because they had to use official corporate hanko.

Japan has seen a number of debates over its COVID-19 strategy. Early on, the mishandled quarantine of the Diamond Princess, resulted in severe embarrassment to the government and both a more serious approach, and a $\$ 22 \mathrm{M}$ propaganda budget to polish Japan's image with foreign media. Another debate was over the "reality" of Japan's pandemic numbers related to the government's fear of losing the Tokyo 2020 Olympic Games, and with the release of fuller figures for Tokyo, it seems excess death rates do indeed indicate that mortality from COVID-19 may have been 15-20 times the official figures. The reason for this undercounting is linked to one of the most persistent controversies - the decision to limit PCR testing to cluster-tracing not individual diagnosis. The Abe government discouraged the latter on the grounds that it would overwhelm local health services. Deep cuts to those services over the last 25 years 
since the 1994 Community Health Law may indeed have left Japan's health system unable to cope. The lack of preparedness and cuts in local funding, which has meant a shortage of accessible critical care beds, leading to some tragic consequences, demonstrated by the unnecessary death of sumo wrestler, Shobushi, as well as a lack of knowledge of actual death rates.

Even so, Japan remains relatively successful by world standards. A "cultural hypothesis" may go some way to explaining this apparent success, particularly the propensity towards distance and reserve (no skin-to-skin contact) and the fact that wearing non-medical face-masks was already normal for anyone with disease symptoms, to protect others. However, cultural factors have not all been positive, with widespread exclusion and bullying of those with COVID-19 and even of healthcare workers.

High technology has however played a significant role in communication. The government has relied heavily on LINE to distribute information about COVID-19. LINE is a messaging system created by the Korean NHN (now Line) Corporation, that grew from in-house response to the 2011 3/11 earthquake, tsunami and nuclear disaster, to being pervasive in Japan, with multiple functions including payment systems, a position that was cemented in 2020 by the merger of Line Corp with Yahoo Japan, the other major social media corporation in Japan (a separate company from Yahoo in the USA). Both the national government and the Tokyo Metropolitan Government have created COVID-19 dashboards, which provide information about infection and death rates (however dubious), as well as information about regulations, and recommendations for behaviour. Japanese government policy has long depended upon such moral suasion campaigns, now fully digital as well as in traditional poster forms.

Finally, Japan launched a contact-confirmation app, but it was not a simple story. In early May the outlines of an app called "Mamoriai" ("Protecting Together") were made available. It was created by NGO, Code for Japan, and backed by the Rakuten corporation. Based on the Apple-Google API, it was a decentralized app, using on-phone storage, anonymized data, and no tracking the user outside of localized (bluetooth) contact between users. It was adopted by government and heralded as the official app, but when the government finally released an app, in mid-June, it was not Mamoriai, but a different app, "Cocoa" which, while still based on the Apple-Google API, appears to be a parallel scheme developed by Microsoft employees. Exactly what happened, and the implications, are still unclear.

Contact tracing apps are intrinsically flawed as a strategy and Japan's response has settled on a less risky not risk-free technological solution as it emerges from its State of Emergency. This may all turn out well or badly - either way, it will be despite, not because of, the Abe government's shifting, evasive and unclear strategy during the pandemic.

\subsection{Kenya}

Douglas Kimemia, Virginia Commonwealth University, kimemiadk@vcu.edu

Africa faces the world's most dramatic public health burden, given its constant fight against recurring and infectious diseases. Africa faces a preponderance of risk factors - high levels of poverty, urban density, overcrowded informal settlements, and limited access to healthcare - that combined threaten to exacerbate the pandemic on the continent.

In response to the pandemic crisis, Kenya followed the global trend of imposing shutdowns of businesses and human movements. As COVID-19 continues to spread around the world, so too have rumors, misinformation, and fake news about the pandemic. To keep the citizens informed, the Minister for Health, Mutahi Kagwe has been holding press briefings almost daily to update the country on the number of tests completed and positive cases. The numbers authenticity has been questioned by the politicians and other people, who argue the government is using unreliable testing centers with results are contradictory and lead to presumed cases being quarantined in government facilities. 
The government has relied mostly on the vernacular radios to disseminate the information, especially in the rural areas where people have less access to TVs and the internet. There are commercials on social media to reach out to young people. This has led to an information divide and failure of fact-checking, especially for the elderly who are also especially vulnerable to the disease. The information received is also processed differently in different regions due to language differences, and also the ever-changing landscape of the virus. To counter this misinformation and the information divide, the Ministry of Health has established a portal for accurate reporting. There are sixty guidelines and protocols posted on the portal. These guidelines include information like the importance of wearing masks and other protective equipment and hebhaviours. The core idea behind this initiative is to ensure a greater level of public awareness.

The critical issue is how to transmit the information reliably to people who have no access to the government's websites due to lack of time, access and illiteracy. The information is written in English, which is a second language to the majority of Kenyans. There is a need for the government to translate the information into Kiswahili, which is a national language. While a significant number of Kenyans have access to cell phones, the internet remains expensive and inaccessible in some areas. The majority of the people are unlikely to visit the portal to check the most recent guidelines and they are more likely to rely on the informal means of communication.

Patient tracing is not a new concept in Africa as it was first used in the Ebola cases in West Africa and proved to be very successful. However, the discussion surrounding the citizens' privacy has not been robust. Human Rights groups have warned that the state's heightened surveillance measures to monitor citizens during the coronavirus pandemic could result in abuse. This is especially the case as there are no regulations or guidelines on how to monitor the usage of these applications in relation to protecting citizens' privacy from abuse. The technology or the application of patient tracing has been a bit like the 'wild west' as the government has left the app development to the entrepreneurs and universities. In early May, a local university launched a computer-based contact tracing case management application to help address the COVID-19 pandemic. Also, in early May, two youths developed an app dubbed Myride Africa, which can be used by public vehicles. Additionally, other apps are circulating in the country targeting different service areas. Most Kenyans are not aware of these many apps and how they impact their privacy. The Kenyan government has not openly talked about who is financing these apps or how the government relates to the developers. There are no reported statistics about the extent of their usage within the country or how to make the process of using these appa transparent.

The Kenyans look forward to the new normal as the country reopens its economic activities and human movements. As the government loosens most of the restrictions it is yet to see the real impacts, especially on the economy and in relation to new infections.

\subsection{Mexico}

Luis F. Luna-Reyes, University at Albany SUNY (USA) Universidad de las Americas Puebla (Mexico), luisf.luna@udlap.mx

The first case of COVID-19 in Mexico was registered on February 28. The pandemic was interpreted by the President as a fabricated problem to introduce instability in his mandate. As a consequence, the closing of businesses and social distance recommendations faced contentious statements by the President and State Governors. For instance, on the second day of business closing (March 18), the President commented: "Honesty is the protection [against Covid]... Look, this is my protection [showing a prayer card]... this is a gift from the people, and it is not just catholic, I keep here [in my wallet] evangelical 
cards and others from freethinkers..." On the next day, he described the pandemic as a negative campaign promoted by the media and political interests against his administration. Such a politicized view of the problem promoted lack of coordination among the States and erratic application of policies and recommendations with very limited citizen support. Economic impacts have been at the center of all discussions and fueled further polarization. Both political and economic pressures have pushed the country to reopen under the so-called 'New Normal' policy since June 1st, in spite of the growing number of cases.

Government policies have been supported by data from the Ministry of Health Information Systems, following what the Ministry of Health has called the "Sentinel Data Model." The model gathers information from 26,000 clinics across the country, which report total cases of respiratory diseases in each unit. A sample of those units runs tests confirm the prevalence of COVID, and sample data is used to estimate national numbers. The Sentinel model is built on the assumption that mass testing is a waste of resources, and as a consequence, not enough test kits have been made available to the public. Given the politicization of the pandemic, the Federal Government accepts these estimates as the only truth. Unfortunately, citizens distrust the official numbers, and their bias towards under-reporting is continuously reported by the national and international media.

The 'New Normal re-opening protocol is guided by another information system with a granularity at the state level. The COVID Dashboard shows levels of risk as colors (red, orange, yellow and green) resulting from the aggregation of four indicators: hospital occupation, positive cases as a fraction of suspected cases, trend on hospitalization and trend on new cases. The dashboard is the result of the collaboration of the Ministry of Health, the Mexican Council for Science and Technology and the 32 State Governors. Citizens not only distrust the data, but perceive coordination as a political strategy rather than a public health concern. Although most States are in Red or Orange, the President invited all citizens on June 13 to "go out to the street and continue with their regular activities, living without fear [..] follow recommendations from the health authorities according to your own judgement."

Traditional media has been at the center of continuous updates to the citizens, through a daily news briefing, with the Ministry of Health's website acting as a repository of information about the epidemic and preventive measures. Mobile apps have been developed at the federal and state levels by a diversity of public and private actors, and they provide information about COVID-19 and self-screening tools. The federal government app has an opt-in option to share data from the app to a repository although it is not clear how the information is being used to guide policy. There is no single repository of data gathered by all the apps and there has been no public concerns about data privacy. Apps do not seem to be widely used, the Federal app shows half million downloads from May 25 to June 15 in a country of 126 million people.

In sum, both information systems and policy during the pandemic have been politicized by power groups, and highly questioned by the media and society. These two realities have led to an uneven application of policy that jeopardizes both public health and economic outcomes.

\subsection{Netherlands}

\section{Albert Meijer, Utrecht University, a.j.meijer@uu.nl}

The COVID-19 pandemic manifested itself in March in the Netherlands. From March 12, the Dutch government took a broad range of drastic measures to stop the spread of the disease and reduce social interactions to a bare minimum. The 'lockdown' was relaxed step by step from May onwards when first the primary schools were re-opened on May 12, after that the secondary schools and restaurants on June 
1st. In the first months of the crisis, testing facilities for corona were limited. For this reason, people were generally discouraged to get themselves tested for corona. Overall, there was some discussion about the consequences of these measures for the economy but there was mostly broad support and most people followed the rules.

During the lock-down, information technologies were used to support policies and operational processes. The National Institute for Public Health and the Environment (RIVM) used a host of systems to process information as a basis for model building and crisis policies. A system that played a role at the operational level was developed by a hospital in Amsterdam to help people to establish whether they had symptoms of corona and communicate about these symptoms with the hospital. In this period, there was some public discussion about information systems. The use of police drones to see if people were outside in groups were criticized as being unacceptable instruments of surveillance. And a system that the Ministry of Health introduced to promote the national management of intensive care hospitals beds was criticized for not being effective and even dangerous by providing incorrect information about the availability of beds.

When the government started to develop policies for relaxing the lock down measures, information technologies came to play a more strategic role. Two key instruments were presented at national conferences as crucial elements in national policies for dealing with the COVID-19 crisis: a corona app and a corona dashboard.

The corona app was enthusiastically introduced by the Minister of Health in a national press conference on April 7. In the weekend of April 18, the ministry organized a public appathon for which eight companies were invited and who were questioned by invited experts. On lifestream, thousands of people watched it and posed additional questions. This appathon resulted in much discussion on various (ethical and sensitive) aspects of the app such as privacy, the consequences for social relations and the security. Some viewed the appathon as a failure since it did not produce a useful app. Others highlighted that the appathon was as an innovative way of organizing democratic participation in the development of high-tech policy instruments. The development of the app CoronaMelder continued quietly and in the beginning of July it underwent small-scale tests. The expectation is that the app will be made nationally available in September.

At the national press conference on the COVID-19 crisis on May 19, the Minister of Health highlighted the need to build a corona dashboard to monitor the spread of corona. The minister talked vividly about the value of the dashboard and compared it to the dashboard of a car. It was meant both as a tool for national decision-makers and for informing the public. The dashboard is to provide information at a regional level and as such formed the basis for specific interventions to limit the spread of the disease. The public dashboard was introduced in June (https://coronadashboard.rijksoverheid.nl/).

In sum, there was broad support for the government's management of the corona crisis and discussion about the use of information technologies. The fear of privacy intrusions played an important role and Asian examples were seen as undesirable futures due to their emphasis on surveillance. These concerns were taken into account in the process of developing an introducing information systems but they did not stop the development. At the moment, there are no indications that the corona app and the corona dashboard have made a significant contribution to the management of the corona crisis.

\subsection{New Zealand}

Karl Löfgren, Victoria University of Wellington, karl.lofgren@vuw.ac.nz

In the second half of March, following a rising number of cases of COVID-19 in New Zealand, the country was effectively put under a state of national emergency on 25 March. The national emergency 
was accompanied by the introduction of an alert level system specifying which the public health and social measures were to be taken depending on the level of containment and control of the disease. On 25 March, the country went straight into level four - lockdown of the country - which was gradually eased, and a complete removal of all restrictions 2 June. In addition to these measures, there has been a travel ban on travelers from China since January, and from all other countries since March (citizens and permanent residents excluded), and extensive testing of anyone with symptoms. With a limited number of cases, isolation and termination of existing clusters of infected individuals, only a limited number of reported deaths, and not at least an active prime minister calling for empathy and understanding, the New Zealand response has been celebrated as a model for how to tackle the virus infection. Like some countries, New Zealand has adopted a transparent approach about the state of the virus with a digital 'dashboard' with updated information about the transmission of the virus and cases (https://nzcoviddashboard.esr.cri.nz).

One of the arguments for the sharp lockdown of the country was the combination of a) the imminent risk of community transmission, b) the absence of an efficient vaccine, and c) the lack of tracing and tracking capacity (being the only method of keeping the virus at bay). As the country begun to lift some of the restrictions, allowing more services to become available to the public, it became clear that some kind of tracing system would be needed. Another important driver was the reports from Asian countries, and in particularly South Korea and Singapore, being successful with their use of smartphone apps for contract tracking.

The Ministry of Health (MoH) begun to develop a digital solution in April and presented in May a national contact tracing application containing a smartphone app, a website and a data platform. Unlike similar platforms overseas, there was a clear ambition from the very beginning to retain 'consumer' choice and trust, and to minimise the collection of private information to those matters most directly useful to contract tracing processes. The platform also ask for a few personal details and all the contract information is stored on the device - not transmitted elsewhere. Rather than being a tracker, it has been presented as a 'digital diary' The system went live on 20 May, two days after the country had come out of most of the restrictions.

While the rapid and hard response to the virus in New Zealand probably can be presented as a success, the tracing app represents an almost classic story of implementation challenges in the public sector. First, the MoH solution was launched too late given that business had to operate with some kind of tracing system from day one. Consequently, many businesses, in particularly in the hospitality industry, had already chosen other apps, or just paper-based solutions, for tracing their customers. While the effectiveness of the app relies on a majority of the population using it, the number of downloads suggests that less than ten per cent have. Second, not even all public authorities have chosen to make use of the app. The two biggest public health providers in New Zealand have chosen to use their own tracing systems resulting in challenges sharing data. Finally, not only are there digital divides at play with respect to the number of people owning the necessary smart phones, the app has also been heavily criticised for being difficult to use for people with vision disabilities. The app has so far not been subject to too much political debate, but that has more to do with the fact that its value is considered to be low given the almost complete current elimination of the virus.

\subsection{South Korea}

\section{HeungsukChoi, Korea University, hschoi@korea.ac.kr}

The first confirmed case of COVID-19 in S. Korea was a Chinese lady from Wuhan, China who flew to Seoul for a tour. She was diagnosed on January 20, 2020. The second confirmed case occurred on 
January 24. It was a Korean man who flew into Kimpo International Airport of Seoul from Wuhan. The South Korean government instigated "the Central Accident Control Headquarter(CACH) for Corona virus contagion," which is led by the Minister of Health and Welfare, and raised its contagious disease crisis level from "alert" to "guard" on January 27. The CACH then quickly decided to check up all the 3032 travelers who entered from Wuhan during the period of January 13-26. As the S. Korean government had to raise its contagious disease crisis level to "serious," it put into operation the Central Disaster and Safety Countermeasures Headquarters(CDSCHQ) led by the Prime Minister on February 23. As of July 10, 1,384 thousand people have been tested to result in 13 thousand cumulative cases of COVID-19 infection in South Korea where 50 million people reside. The number of COVID-19 patients in treatment is 985.

While the government was working on to control COVID-19, the first and second mobile COVID-19 apps and websites showing the sites of visits by COVID-19 patients, their means of transport, etc. were created by university student entrepreneurs and put on the market on January 30 and February 2. Notwithstanding, most local governments put such information on their websites and provide each citizen with brief push-messages these days. An emergency-approval for a COVID-19 diagnosis kit was given by the Ministry of Food and Drug Safety on February 4. The diagnosis kit was developed by a bio-medical SME and tested by Korea Centers for Disease Control \& Prevention(KCDC). The emergency approval procedure was established after experiencing MERS, which killed 38 people in 2015. As of June 25 , the website of the Ministry of Health and Welfare enlisted 65 S. Korean COVID-19 in vitro diagnostics device manufacturers and exporters.

South Korea is a country where $95 \%$ of its population use smartphones, and credits cards, rather than prepaid transport cards, are widely used for public transportations. Besides, the Home Tax System of its National Tax Service let individual citizen do tax reporting with few mouse clicks. This creates an ideal environment to track the sites of visits, as well as means of transports, of COVID-19 patients. Once those sites of visits and means of transports are identified, it even becomes possible to track down those who have possibly come across COVID-19 patients. Notwithstanding it would require additional effort, it was how the Seoul Metropolitan Government and KCDC, in cooperation with Korea Telecom, managed to send SNS messages encouraging voluntary COVID-19 check-up to those who visited the Itaewon area on the day when contagions occur in a few dance clubs in Itaewon.

At the outset of the COVID-19 outbreak, the S. Korean government adopted an open data policy for complete transparency. It had a very painful lesson from the MERS outbreak where it faced very strong public complaints by not revealing the names of the hospitals that MERS patients dropped by indeed. Such an open data policy is still put in place, public dashboards for COVID-19 being established and keenly updated at the central and local levels. It could be maintained that the open data policy has been instrumental to effectiveness in controlling the spread of COVID-19.

The whereabouts of individual COVID-19 patient are monitored by KCDC and put on the websites of local governments in anonymous form. The outcries for privacy are increasingly put forth by some NGOs, professional and academic societies, etc. Besides, serious complaints are filed by the owners of shops and restaurants who feel that their businesses are unjustifiably adversely affected by the public data reporting the past visits by COVID-19 patients. There exist at least anecdotal evidences that show the central and local governments are becoming much more sensitive to privacy issues, as well as unjustifiable business impacts of the open data policy. It seems, however, that the pursuit of effectiveness in controlling the COVID-19 has been dominating the atmosphere so far. Could the path have been different, so that more weight was put on privacy? It might have been coincidental that the Shincheonji church is generally regarded heretic, and some of those dance clubs in Itaewon were gay bars. It seems, however, that these coincidences might well create less favorable social and political atmosphere for privacy arguments. 


\subsection{Singapore}

Aarthi Raghavan, National University of Singapore, aarthir@u.nus.edu

Mehmet Akif Demircioglu, National University of Singapore,mehmet@nus.edu.sg

Singapore saw the first confirmed case of coronavirus on January 23. While the earliest cases were imported from Wuhan city, in China, the disease soon started spreading locally in February and March. The government targeted identified local clusters and achieved significant decline in cases. However, in late March and April the number of cases spiked again due to mass transmission among migrant workers staying in dormitories. As of June 27, the country has 43,246 confirmed cases and 26 deaths. While an advanced healthcare system is a key reason for a low death rate, the government's proactive adoption of technological solutions has ensured prevention and contact tracing.

Singapore developed an early text and mobile web-based software solution on February 10 which enabled people under quarantine to report their location to government. While the Ministry of Health has been sharing case data on its website since the beginning, an individual dashboard has also been developed on UpCode Academy (https://co.vid19.sg/singapore/) which uses official data to break down specific trends. The Ministry of Health provides daily updates on Covid-19 from the following website https://www.moh.gov.sg/covid-19. Government also launched a contact tracing app in March, known as TraceTogether, to allow authorities to identify people exposed to the infection. Additionally, Telemedicine which used video consultations of health issues helped people with comorbidities avoid hospital visits. In May, a robot named Robodog, or Spot, designed by Boston Dynamics, was deployed in public parks with prerecorded messages encouraging people to maintain social distancing. Whilst this started on a trial basis, officials are considering wider use of the robot for other public places.

Singapore launched an extensive nationwide testing strategy which covered nearly 12 percent of the population as of June 28. The government has also developed SafeEntry, a national digital check-in system for people visiting malls, restaurants, coffee shops, supermarkets, parks, and other places. A dedicated website (https://www.flugowhere.gov.sg/) was also deployed, to help people search for clinics and access affordable treatment for all kinds of respiratory infections. More recently, efforts have been in the direction of better contact tracing through wearable devices, which may potentially lead to stricter measures then those observed in Europe.

As of late June, nearly 2.1 million people (nearly 37 percent of the population) have voluntarily downloaded the TraceTogether app, although experts believe that downloads have yet to reach a critical threshold (60-75 percent of the population) to have meaningful impact. Data privacy concerns have reportedly limited the use of TraceTogether app, although it has user privacy at the core of its design. Critics have also pointed out that the app may not be effective as it can generate false positives owing to flaws in Bluetooth technology. Moreover, the Personal Data Protection Act (PDPA) in its current form allows organizations to collect, use and share personal data of users without consent. In general, there is broad consensus on using secure technological solutions to curb the spread of the disease, with robotic and web-based solutions well-received by the public.

The app has been updated with new features in Chinese, Malay, and Tamil languages - other official languages in addition to English- to encourage wider use. Recent debates in the country on the effectiveness of the app discussed a technical glitch in Apple smartphones that has limited its adoption. While government is working together with Apple to fix this problem, officials have declined calls for making the app mandatory. It is believed that this will limit the app's reach and purpose. In the meantime, the Singaporean government is considering nationwide distribution of wearable contact tracing devices to make social distancing more feasible, inclusive, and effective. 


\subsection{Spain}

\section{J. Ignacio Criado, Universidad Autónoma de Madrid, ignacio.criado@uam.es}

According to international evaluations, Spain has a leading role in the use of information and communication technologies in government, and during the COVID-19 crisis this has been one the main issues at stake. Spain is a very decentralised country with 17 autonomous communities (regional governments), all of them having extensive managerial powers in health policy. Spain was one of the first European countries to be hit by the pandemic. On March $14^{\text {th }}$, the Spanish Government declared the "state of alarm" and a day later started a very strict lockdown, with the confinement of the population and a set of measures restricting the mobility of individuals. Also, the Ministry of Health was officially declared the "competent authority" and its Health Alert and Emergency Coordination Centre (created in 2004), took control over the major strategic health decisions.

At the start of the crisis, the debate concerning the use of technologies to fight COVID-19 turned concentrated on the provision of public health information. In the first place, the Spanish Government used social media to provide information, promote public service and to collaborate with citizens. The hashtag \#InfoCoronavirus was launched early in March by the Ministry of Health @ sanidadgob and @ SaludPublicaEs or the whatsapp chatbot Hispabot COVID19 to answer questions about the disease. Other ICT issues at this initial stage were the effectiveness of public information and collaboration using websites and apps, providing early diagnosis of coronavirus symptoms, mitigating the workload of emergencies services (112 call centres), and restricting the access to primary care centres and urgencies in hospitals for the most difficult cases. From the outset, the implications of the use of these websites and apps in relation to personal privacy were raised by the Spanish Data Protection Agency.

During the lockdown in Spain, ICTs started to play an additional role in analysing mobility patterns. In April the Spanish Government developed a system, in collaboration with the major telecommunication providers in the country, previously experimented for the National Institute for Statistics, to monitoring the mobility of citizens via GPS and mobile phones signals. Daily reports were made available in the form of a public dashboard. Also, these results were used to control and evaluate the confinement, and to strategically use big data to understand the potential patterns of future development of the disease.

The need for a trace and track system app was debated during the latter stages of the health crisis. The Spanish Government has publicly supported an app to monitor the evolution of the COVID-19 with the coordination of the Secretary of State of Digitalization and Artificial Intelligence. Whilst different solutions have been assessed and adopted by other European governments, the app developed by the Spanish company Indra was endorsed by the Spanish Government. This app is now being tested in the Canary Islands, and will use the Decentralized Privacy-Preserving Proximity Tracing (DP-3T), bluetooth technology, in order to keep to a minimum the personal data gathered, and in order to follow the interoperability standards of the EU. This project initiated a healthy public debate about the privacy of personal data, in a country with tradition of having a very restrictive approach to such issues.

In summary, in the case of Spain there has been a polarized debate regarding to the government's management of the crisis and the use of ICTs. Initially, the number of infections and deaths was higher than most other countries opening up a discussion about the desirable start date for the lockdown. This was followed by a debate about ICTs and the collection of personal data which has slowed down the implementation of the trace and track app. Health authorities have expressed reservations about using such systems, because the percentage of the population required to voluntarily download and use the application to make it functional, and also because of the problems associated with accuracy and effects of "false-positives". This is perceived as especially problematic in a potential second wave of the disease. 


\subsection{Sweden}

Ola Svenonius, Swedish Defence Research Agency, ola.svenonius@foi.se

The first confirmed case of SARS-CoV-2 in Sweden is dated as January 31. By March 15, the government declared that Covid-19 was spreading on a societal basis, with an epicenter in the Stockholm area. Sweden has adopted a liberal strategy in comparison to many other countries. The foremost reason for this is the absence of a state of exception in Swedish basic law and the general provisions laid down in the Communicable Diseases Act. The Swedish approach puts a high reliance on the individual citizen's responsiveness to disease control instructions. It enjoys high acceptance among the general population, but there is a growing concern regarding the number of infections, especially among the elderly and socially disadvantaged groups.

The most important actor in Sweden is the Public Health Agency (FOHM). Information to the public is mainly communicated through the regional health services and the interagency crisis information site Krisinformation.se. In addition, the FOHM maintains a Covid-19 dashboard where aggregated Swedish data down to municipal level is provided. Swedish authorities have had difficulties solving logistical problems with tests during the crisis. At first, testing focused on medical staff and high-risk groups. Only as of June have tests become widely available for the general population. From an information technology perspective, two instances stand out in the Swedish case: the mobility tracking using aggregated cell phone data, and the failure to present a "Corona app" similar to those in other countries.

The first critical test of the Swedish corona strategy - i.e. whether people actually altered their behavior voluntarily because of the pandemic - was the Easter holiday. To track whether people stayed home, the FOHM received aggregated cellular data from Sweden's largest phone operator Telia. These data showed that the population at large obeyed the instructions at that time. The use of cell phone data for mobility tracking was controversial, since it is the first time for this kind of data sharing in Sweden. Both private and public representatives have taken great lengths to reassure the public that the data is anonymous and that it is impossible to re-identify people. Since Easter, the use of cell phone data has been a recurring aspect of Swedish corona crisis management, and is now considered quite effective as a monitoring tool. The crisis thus paved the way for new public-private partnerships in the wake of the pandemic.

By the end of March, the Civil Contingencies Agency (MSB) began working on a corona app, similar to those used in other countries. A month later, the finished app - a self-estimation tool - was put on hold, because the FOHM claimed not to be in need of the data. Little is known about the technical specification of the app, since it has yet to be released, but it is claimed that much of the data it generates is already collected elsewhere. The mismatch in expectations and intentions between the MSB and the FOHM was widely interpreted as a failure to cooperate between the two agencies. There were also ethical and political reasons for rejecting the Swedish app. Ethical, because the question arose whether the collection was permissible according to the EU GDPR, and political, because the Swedish government awaited a European digital tool, and did not want to invest in something that would quickly become obsolete. The public debate regarding the use of information technology has mainly focused on the use of mobile phone tracking, and partly regarding privacy of the cancelled MSB app. A serious debate on surveillance has yet to materialise.

In sum, the Swedish reliance on information technology during the corona crisis unveils several aspects of the Swedish legal and political culture, not least concerning the use of information technology. Ethical issues did play a role, but far more important was the political debate on lack of medical stockpiles, limitations of the Swedish model of crisis management, and the failure of state agencies to cooperate. 


\subsection{Turkey}

Mete Yildiz, Hacettepe University, myildiz@hacettepe.edu.tr

The first COVID-19 case in Turkey was identified on March 10. Days later, the Turkish government announced drastic measures including the temporary closure of all schools (from daycares and primary schools to universities) and many businesses, reorganization of sports events to be performed without spectators, a halt to many domestic and international flights, and travel restrictions within the country. Public and private hospitals conducted COVID-19 tests free of charge, subsidized by the government. As of June 30, 3.4 million people (4\% of the population) have been tested.

Despite the lack of a nationwide lockdown, the Turkish government announced localised lockdowns in 31 major cities, where over two-thirds of the population live. These lockdown were during weekends and holidays, as well as curfews for older people $(+65)$, patients with chronic diseases and people under the age of 20 . The restrictions were eased incrementally after May 11, most notably the lifting of lockdowns and travel restrictions on June 1st. Although the COVID-19 crisis hit Turkey during an economic downturn, Turkish people understood the necessity of these restrictions and mostly abided by the rules.

Turkey effectively used information technology to deal with COVID-19-crisis. The Ministry of Health provided daily COVID-19 updates in the form of public dashboards linked to its official website and social media accounts. Also, both the Scientific and Technological Research Council of Turkey (TUBITAK) and the Council of Higher Education (YOK) launched COVID-19 portals to provide information, publish COVID-19 research and answer questions from the general public. Hacettepe, a leading public university well-known for its state-of-the-art hospitals, created a Q\&A website where citizens' COVID-19 questions were answered in short videos by Hacettepe's expert medical personnel.

A mobile application developed by the government, aptly named Life fits into home, enabled its users to monitor whether there are infected people in their neighborhoods and their illness status through an on-line map. This application, which was introduced on April 18 and downloaded by 6 million users, also provided warnings in case of proximity or contact with infected individuals. The application was generally favorably received and caused no serious public debate other than user calls for updates to make it more user-friendly. Citizens used the national e-government portal to apply for free face masks, financial assistance, and QR code permits for intercity travels or public agency visits during lockdowns. Finally, a crowdfunding website was launched that collected more than 2.1 billion Turkish liras (approximately 274 million Euros) from more than 900.000 individuals and organizations via SMS donations and money transfers.

There was awareness and discussion that certain countries were using the COVID-19 crisis as a window of opportunity to strengthen its state surveillance practices, and as a consequence it was emphasized that Turkey's applications would not be mandatory. There was no noteworthy political debate about the application and its risks, however the voluntary application was downloaded by only 6 million people, which is $7.2 \%$ of the population. However, the overall Turkish public opinion about the role of information technology in dealing with the COVID-19 crisis has been positive, as they, in general, welcomed the use of these new applications to cope with the COVID-19 pandemic. For example, since the mobile application shares the location and the health status of the infected individuals anonymously, not many people or organizations raised ethical and privacy concerns. They are mostly percieved as more convenient wasy of doing things. For instance, using the e-government portal to apply for face masks, financial assistance, and travel permits is widely seen as an easier, faster, and much safer way of performing the tasks usually done face-to-face through conventional bureaucratic or market mechanisms. 
As of June 30, there are no systematic studies or performance data about the value of information technologies in fighting the pandemic in Turkey. Although the contribution of information technology in dealing with the COVID-19-crisis is unclear, the Turkish people appear to embrace the use of these technologies without any specific concerns.

\subsection{United Kingdom}

William Webster, University of Stirling, william.webster@stir.ac.uk

The COVID-19 pandemic took hold in the UK during March 2020. Initially the UK Government was slow to react whilst it deliberated on public policy options, but initiated an extensive 'lockdown' on 24 March. This included financial support for businesses and strict measures on 'social distancing'. The easing of the lockdown started in June with some non-essential shops reopening and some pupils returning to school. The different nations of the UK (England, Scotland, Wales and Northern Ireland) implemented differentiated lockdown rules and have subsequently relaxed these at different times. In general, citizens have supported the lockdown and there has been a healthy debate about its economic consequences and the point at which certain business sectors can become active again. A nationwide 'contact-tracing' testing system was been established. This has proven to be contentious due to the accuracy of the system, the willingness of individuals to self-isolate and the number of tests desired by government compared to the number of tests actually undertaken. Throughout June, and following the Dominic Cummings revelations, there has noticeably been less public support for social distancing measures, coinciding with nationwide Black Lives Matters protests.

New ICTs have been prominent in the management of the pandemic. The Scientific Advisory Group for Emergencies (SAGE), which provides scientific and technical advice to support government decision makers during emergencies, has utilised a range of information systems to support scenario planning, forecasting and public policy, although there has been tension between the scientific and political impetus behind certain decisions. The Government created an online COVID-19 Dashboard showing daily statistics on cases of coronavirus and deaths associated with coronavirus. This data has formed the basis of daily Government briefings, although there has been concern about underreporting in the statistics. Surveillance technologies have been used to enforce lockdown rules, drones have been used to monitor remote beauty spots, ANPR has been used to identify drivers inappropriately travelling long distances and there has been discourse about whether thermal imaging can be used to detect infected citizens.

New digital technology has been a core element of the strategy to oversee the relaxation of the lockdown. Considerable emphasis has also been placed on the development of a UK built Corona virus 'Contact Tracing App' designed to operate on the mobile phones of citizens. The app aimed to slow the epidemic, control the flow of patients into hospitals, help people return to normal life and gather secondary data for use by the NHS and strategic leaders. Once installed, the app used Bluetooth to keep a record of people who came into close contact with one another - so long as both parties had installed the app. The app was intended to be operational in the early part of April and undertook initial feasibility trials in the Isle of Wight. From the outset there were concerns about the levels of state surveillance and about a lack of the legally required Privacy Impact Assessment. These concerns were manifest in public and media debate about its efficacy and why the Government was being so dogmatic about insisting on a bespoke UK system. By mid-June, and with no sign of the app becoming operational, the Government signaled a radical change of direction, by announcing that the UK would utilise the decentralized system created by Apple and Google and that there would be no definitive start date in 2020.

The failure of the UK designed app can be explained by a number of factors. Using Bluetooth in this way was untested and it became apparent that users were reluctant to switch on a feature that drained 
battery capacity so quickly. The proposed system was distinct from others in that it was centralized and made personal data available to public authorities, thereby raising alarm amongst privacy campaigners. This policy failure was fueled by a governmental post-BREXIT desire to develop UK solutions to problems and a populist approach to decision-making, which emphasised policy announcements over evidenced activity.

\subsection{United States}

Mila Gasco-Hernandez,University at AlbanySUNY,mgasco@ctg.albany.edu

The United States reported its first coronavirus case on January 21 and its first death only a few weeks later, on February 29. Although on March 13, Donald Trump declared a US national emergency, no further drastic measures were taken at the national level. Response to COVID-19 came mainly from the states, most of which issued stay-at-homes directives by March 30. Testing policies followed the same pattern: the federal government held individual states responsible for planning and carrying out all coronavirus testing. But different states adopted different approaches. Further, despite significant efforts by some states, such as New York and New Jersey, testing did not meet the demand. The lockdown looked therefore very different in different parts of the country and so did the reopening that started in most places around Memorial Weekend. In an electoral year, discussions about when and how to reopen the economy highly reflected the country's political and social division.

In general, the United States fell behind other countries in the use of information technologies to map infections and model the virus spread. Efforts were dispersed and were not led by the national government. Although the White House announced in early April the creation of a national coronavirus surveillance system, the project was soon criticized for the involvement of the private sector and data sharing and patient privacy concerns. Instead, different agencies and research institutions used their own databases and dashboards with monitoring purposes. For example, the Centers for Disease Control and Prevention used multiple surveillance systems run in collaboration with state, local and territorial health departments, public health, commercial and clinical laboratories, vital statistics offices, health care providers, emergency departments and academic partners. One of them was the CDC COVID Data Tracker (https://www.cdc.gov/covid-data-tracker), which provided an accurate overview of, among other, cases and deaths by state and county, tests performed, trends, school closures, and social impact. Similarly, Johns Hopkins University established the Coronavirus Resource Center (https://coronavirus.jhu.edu/) to help advance the understanding of the virus and inform the public. The website included a COVID-19 Case Tracker, updated daily in near real-time for both the world and the United States.

As states began to open, the use of information technologies, and particularly monitoring dashboards developed in-house, became more important to support policy and decision-making. Yet, each state was different and used their own databases, which they made available to the public, to inform policy. For example, in the framework of the program Move New York Forward, New York State, one of the most affected states in the country, built an Early Warning Monitoring Dashboard that provided detailed information by region about the criteria that guided phased reopening in the state: testing/tracing targets, new infections, severity of infection, and hospital capacity (https://forward.ny.gov/early-warningmonitoring-dashboard).

Contact tracing apps were also off to a slow start in the United States. In April, North Dakota and South Dakota were the first two states that asked residents to download the CARE19 mobile app, developed by the North Dakota Department of Health in partnership with ProudCrowd, to assist in contact tracing. By the end of May only $2 \%$ of the residents had the app on their phones. Also, in late May, North 
Dakota, along with Alabama and South Carolina, committed publicly to using Apple and Google's contact tracing technology in statewide apps built by government health bodies to slow the spread of the virus. Other states took a different approach. Utah, for example, released its first contact tracing app, Healthy Together, in late April. The app allowed users to share specific location data with human contact tracers. Other states, such Colorado, Florida, and Indiana explicitly stated they would forego digital contact tracing in favor of human-based solutions. Yet, at the time of writing, several states, including California, Massachusetts, and Pennsylvania, are still undecided about digital contact tracing mainly because of concerns of potential violations of privacy. Interestingly enough, there has not been much public debate around these apps although, according to a recent poll, only 29\% of Americans surveyed said they would download and use tracing apps, arguing a lack of trust in organizations to keep their information safe.

\section{Comparative analysis of information responses to COVID-19}

\subsection{Informational responses to COVID-19: Five functions}

The descriptions of the informational responses in these 21 countries highlight an interesting set of government actions. There are substantive differences but also striking similarities in the responses of national governments to the COVID-19-crisis. By focusing on 'informational' activity it is possible to systematically map these similarities and differences and to draw attention to the preeminence of the Information polity. Whilst there are lots of models characterising the characteristics of information and information and communication technologies (Homburg, 2008; West, 2005), here we use a simple analytical framework based on six 'functions' of information management. These are essentially key ways in which informational assets have been utilized by governments to tackle the pandemic.

- Function 1: Management of information for crisis management. Managing information about infections, deaths, hospital beds, availability of pharmaceuticals, staff at the hospitals, etc., is crucial for crisis management responses.

- Function 2: Publishing public information for citizens. Providing information to citizens about COVID-19 cases, hospital beds, deaths, etc. plays a key role in generating support for government policies aimed at restricting contact between citizens.

- Function 3: Providing digital services to citizens. Government portals play a key role in developing healthcare services but also providing financial support and access to other governmental services.

- Function 4: Monitoring citizens in public space. Monitoring public space and the movement of people is a key element in government activities to enforce lockdowns.

- Function 5: Facilitating information exchange between citizens. To enable citizens to adjust their behavior on the basis of possible contamination with COVID-19. In particular the use of 'Corona apps' to facilitate the exchange of information between citizens about the possibility of coming into close proximity with those who have the disease.

- Function 6: Developing innovative responses to COVID-19. The crisis demanded innovative responses and many countries developed specific strategies and interventions for strengthening their innovative capacity.

This model has been developed inductively on the basis of the descriptions of the informational responses to COVID-19 in the various countries presented in this report. The report does not offer a full comprehensive global analysis, but it does offers significant insight into the activity of the information 
polity during the pandemic. The selection of countries was designed to ensure all continents were covered and was determined by the availability of experts in the eGovernment scholarly community. The contributing authors were asked to provide a general overview of the situation, using the basic guide presented in Section 1, and were asked specifically to note three key elements of the informational responses: (1) the existence of a testing strategy as a basis for collecting policy information about COVID-19 (function 1); (2) the creation of a public dashboard with information for citizens and policymakers (function 2); and the development of a 'corona app' as a basis for influencing citizen behavior (function 5). This made it relatively easy to provide a national comparison around three key informational developments.

The analysis of the other informational functions was less systematic and relied on a more inductive approach. A variety of new technologies for providing services were identified such as telemedicine and portals for government aid (function 3). Many other informational developments, such as drones and talking robots, (etc.), were identified as strategies for supporting the monitoring of citizens (function 4). In a number of countries, specific approaches to innovation were mentioned, including hackathons and online platforms (function 6). Here, the national description of these developments form the basis of comprehending governmental responses to the six informational functions set out above.

\subsection{Function 1: Management of information for crisis management}

Managing information is a key aspect of crisis management (Housel et al., 1986; Quarantelli, 1988) and therefore all countries studied here have systems in place for managing all kinds of information related to COVID-19, including the collection of data relating to the number of cases, the number of hospital beds, the number of deaths, etc. A key issue for this function is the capacity of government to manage information well. For this reason, many countries focused on strengthening the management of information, to ensure it accuracy and timely availability. Brazil has strengthened the epidemiological surveillance systems in the states by enabling a flu surveillance system. And, in Japan it was interesting to note that the management of information was achieved by jettisoning high-tech solutions for a paper-based system.

The crisis also exposed weaknesses in the information infrastructure. In Estonia, for example, the government lacked a high-quality and near real-time monitoring system to track and predict the spread of the virus. There were crucial interoperability issues when, for example, the health and police databases could not exchange data, causing inconvenience and unnecessary workload for police. Not all countries were able to realise strong nationally oriented management information systems due to institutional and political issues. In the US, for example, efforts were dispersed and were not coordinated by the national government. Although the White House announced in early April the creation of a national coronavirus surveillance system, the project was soon criticized for the involvement of the private sector and for data sharing and data protection concerns. Instead, different agencies and research institutions used their own databases and dashboards to conduct monitoring of the virus.

Even though the good management information is widely regarded as a necessity for adequate government responses, a common controversial issue was the amount of testing that had taken place. From the perspective of reducing uncertainty, collecting information through testing makes a lot of sense, but the studies presented here highlight that there were significant differences in the amount of testing taking place. In Mexico, for example, the government's strategy is based on the assumption that mass testing is a waste of resources, and as a consequence, a limited number of test kits have been made available to the public. In South Korea, on the other hand, extensive testing was seen as crucial to managing the 
Table 2

Status of public information about COVID-19

\begin{tabular}{ll}
\hline \multicolumn{1}{c}{ Status } & \multicolumn{1}{c}{ Countries } \\
\hline Government information is public and & Australia, Belgium, Canada, China, Estonia, Germany, Ireland, Italy, Japan, \\
generally regarded as a reliable & Netherlands, New Zealand, Singapore, South Korea, Spain, Sweden, Turkey, \\
& UK \\
$\begin{array}{l}\text { Government information is public but its } \\
\text { reliability is contested }\end{array}$ & Brazil, Mexico, Kenya \\
There are multiple sources of information & USA \\
\hline
\end{tabular}

COVID-19 crisis. It is interesting to note that testing regimes varied considerably between countries that in many other respects are quite similar. For example, extensive testing took place in Belgium whereas testing in the Netherlands was limited.

\subsection{Function 2: Publishing public information for citizens}

Providing adequate information to citizens is generally seen as a key element of crisis management (Perry et al., 2003). Most countries have established a dashboard and used social media and internet platforms to provide accurate and up-to-date information about the crisis to citizens. In many countries, the dashboards are regarded as a reliable source of information. In Ireland, the government immediately adopted a policy of full transparency, thus establishing a high level of trust in its data, and subsequently on the public health decisions made using this data. In other countries, however, public information does not afford the same levels of trust. In Mexico, for example, citizens not only distrust the accuracy of the data presented, they perceive the provision of this information as part of a political strategy. In other countries, such as the US, there is no single trusted source of information and the provision dashboards are regionally fragmented, with individual States using their own databases to inform policy and the public. An overview of the status of public information in each country studied in this report is presented in Table 2 .

\subsection{Function 3: Providing digital services to citizens}

Digital services have been available for some time but generally citizens also had the option to visit government offices (Sá et al., 2016). The lock-down situations in many countries forces them to find new ways to provide services to citizens since the traditional visits to the office of government and public organizations were no longer possible. This resulted in a push for realizing and improving a host of online services for citizens both directly related to COVID-19 (e.g. online diagnosis of the disease) but also indirectly related (e.g. providing economic assistance to citizens who loss their income due to the lock-down).

The combination of the need to provide medical assistance and at the same time minimize the number of movements and contacts between citizens has provide a huge incentive to develop and deliver online telemedicine solutions (Hollander \& Carr, 2020). In Ireland tele-consultations with doctors have become commonplace and in Singapore telemedicine applications were introduced for video consultations so that hospital visits were no longer required.

Government portals have played a key role in providing financial support and other government services to citizens. This was of the utmost importance in a lockdown scenario. In many countries, this worked well. However, in countries where citizens had limited access to the internet, problems associated with the digital divide emerged. In Brazil, for example, the 50 million people that had no access to the Internet were often eligible for certain grants and benefits, but had no way of accessing or applying for them. And, 
many citizens in remote areas in Kenya had limited knowledge of English were unlikely to visit the portal to check on the most current guidelines and information about the pandemic. Instead they were more likely to rely on the informal means of communication.

A specific type of technological development relation to this function was the introduction of chatbots (Park, 2017). The Spanish Government launched the chatbot Hispabot COVID19 to answer questions about the disease via whatsapp. In Estonia, a COVID-19 chatbot was developed for public services on the basis of a hackathon to find useful ICT-based solutions to fight the crisis, and in Brazil the robocall system Telesus is used for classification, diagnosis, tracking, and registration of epidemiological risk.

\subsection{Function 4: Monitoring citizens in public space}

The fourth function concerns the surveillance of society to enforce the lock-down. Many countries have started to use advanced ICTs, drones and robots, to monitor people in public space. In the UK, for example, drones have been used to monitor remote beauty spots, Automatic Number Plate Recognition (ANPR) systems have been used to identify drivers inappropriately travelling long distances and there has been a discussion about whether thermal imaging can be used effectively with surveillance cameras to detect infected citizens. Similar uses of surveillance technologies were discussed for use in the Netherlands and Estonia. In Singapore, new technology was used not only monitor groups of people but also to actively urge them to stick to the rules. For example, a robot was deployed in public parks with prerecorded messages encouraging people to maintain social distancing. In Belgium, speaking drones were used in Brussels to spread messages about social distancing and drones with heat cameras were used to identify people illegally staying in second homes and caravans.

It is also evident that a number of countries sought to obtain access to telephone records in order to follow the movements of citizens (Ienca \& Vayena, 2020). In Spain, for example, during the height of the lockdown, the Spanish Government developed a system, in collaboration with the major telecommunication providers to monitor the mobility of citizens via GPS and mobile phone signals. In Belgium, (local) governments use telecom data to track movements of people and to monitor how population density in shopping streets and at the beach.

\subsection{Function 5: Facilitating information exchange between citizens}

The fifth information function relates to the use of informational systems for monitoring the spread of the disease in society (Sweeney, 2020). In particular, all governments have at the very least, explored the possibility of developing and deploying a mobile phone based 'corona app' to be used on individual citizen's phones. This is a digital intervention designed to influence the behavior of citizens in order to limit the spread of the disease. Corona apps, despite issues about their efficacy, have been a very popular policy intervention in all countries. Typically, these have been developed by government in conjunction with private providers. All governments have explored the value of these apps for their crisis management strategies and only in the US, certain States, such Colorado, Florida, and Indiana have explicitly stated they would forego digital contact tracing in favor of human-based solutions. It is also evident, in the country reports presented here, that contact tracing apps were the most debated and discussed of the technological solutions brought forward during the pandemic. Aspects that attracted criticism included concerns about privacy, mass state surveillance, unclear data responsibilities, competencies relating to the reuse of the data and concerns about the effectiveness of such systems. At the same time, a number of countries only had limited debate about these issues, for example in Estonia, Mexico, Singapore and Turkey. 
Table 3

Type of corona-app by country

\begin{tabular}{ll}
\hline Type of corona-app & \multicolumn{1}{c}{ Country } \\
\hline Centralized & Australia, China, Ireland, Italy, Singapore, Turkey \\
Decentralized & Brazil, Canada, Estonia, Germany, Japan, South Korea, Mexico, Netherlands, New Zealand, Spain, \\
& Sweden, UK, US \\
Commercial & Kenya \\
\hline
\end{tabular}

In general, the country reports highlight there three different approaches: (1) a centralized government approach with all data transferred to a central government database; (2) a decentralized approach with data held only on citizen's telephones, in order to protect their privacy; and, (3) a commercial approach with private apps available to the citizenry. In the UK, the app was originally intended to follow the centralized model, but after resistance and concerns about data processing, this strategy was abandoned in favor of the decentralized app used developed in many other European countries. In Mexico, the federal government app has an opt-in option to share data from the app with a centralized repository. Only in China, was the use of an app compulsory for certain activities, such as taking public transportation. An overview of these different national approaches is presented in Table 3.

The country reports show that in many cases these apps were not yet operational, and where they were, that not many citizens were actually using them. The most advanced patterns of use were found in Asia and Oceania, with for example 10 million users in Shanghai, 2.1 million users (nearly 37 percent of the population) in Singapore and 6 million downloads in Australia and in Turkey. The high usage in China can be attributed to the compulsory use of the app for travel on public transport. Analysis of the effectiveness of these apps for tracking and tracing the disease stresses the intensity of the use of mobile phones in the country and the need for a majority of citizens to voluntarily download and use the apps. South Korea is well placed here as $95 \%$ of its population use smartphones, and credits cards rather than prepaid transport cards are widely used for public transportations and other financial transactions. In countries with less intensive usage, such as countries in Africa and Latin America, the apps can track a much lower proportion of the population. In the country reports it is evident that the Asian countries were leading the way in relation to this information this function. In New Zealand, it was noted that reports from Asian countries, in particularly South Korea and Singapore), were influential drivers for developing a contact tracing app in the country.

It is interesting to note, that whilst most countries developed their 'own' nationally oriented app, many were based on similar technological solutions provided by the big commercial mobile phone companies. Global policy diffusion and transfer has clearly taken place and many countries have adopted policies and technologies that have been successful in other parts of the world. In Ireland they have adopted the German model and in Australia the app developed in Singapore. Other countries, such as the UK, have been determined to develop local technological solutions, which is surprising as the basic functions of the app can be assumed to be highly similar in all countries. The development of these apps also highlights two themes familiar to scholars of eGovernment. Firstly, the discrepancy between the vision and potential of the technological solution when compared to what it actually delivers, and secondly, the increasing reliance of public service providers on the technological expertise of commercial suppliers.

\subsection{Function 6: Developing innovative responses to COVID-19}

The final function identified here does not focus on the informational responses themselves but on novel ways for developing these responses (for a theoretical overview: Yuan \& Gasco-Hernandez, 2019). Various countries highlighted that new approaches were used to promote and develop innovation. 
Estonia organized several hackatons to find useful ICT-based solutions to fight the crisis More than 20 applications including on-line coronavirus questionnaire, COVID-19 chatbots, remote verification for notaries, automatic sick leave letter admission and other projects were developed. The German government organized a hackathon in which 28,361 people collaborated on over 1,300 technological solutions for societal and governmental problems that arose as a result of the virus. This hackathon made it into the Guinness book of records. The Italian government created an online platform where firms and civil society associations were able to provide free digital services for smart working, e-learning, and e-reading.

\subsection{Do informational responses work?}

The key question for all countries is whether these informational responses work. At this stage, the answer to this question is that we don't really know. It is likely that some informational responses presented here will be more successful than others and that judgements about effectiveness and value for money will be determined in the future. To date, as reported by the national experts here, there are no systematic studies or performance data about use of information technologies in fighting the pandemic. This does not stop governments from having great confidence in the value of these informational responses or in promoting their use and capabilities. In many ways, the use of new shiny new digital technology solutions provides evidence that national governments are doing something, regardless of any evidence about their efficacy, to stop the spread of the virus.

\section{Conclusions}

This multi-country report set out to provide insight into the informational responses of national governments to the COVID-19 pandemic. A brief overview of the situation in 21 countries around the world is presented, followed by an inductive comparative analysis of the rich material collected through these expert reports. This final section draws conclusions on the patterns identified, it identifies topics for further investigation and presents tentative recommendations for national governments.

One concluding observation from this multi-country report is that a focus on information and on information technology can act as what John Taylor (1998) refers to as an 'X-ray to study public administration'. An analysis that focuses on information responses generated insights that provide a more general understanding of the public sector in the different countries studied. The analyses highlighted patterns of institutional breakdown in the form of contested information, lack of support for government interventions and federal government leaders who criticized responses at the state level (US, Brazil, Mexico), patterns of institutional dominance when responses were not - or could not be - contested and governments did not tolerate any deviance from its prescribed behavior (Singapore, South Korea, China), and patterns of institutional democracy (various European countries, Canada and countries in Oceania), where informational responses were largely accepted but specific responses were contested and, in general, there was a call for more attention to privacy and other public values. The informational responses help us to analyze institutional differences between the countries.

A second conclusion is that information responses cannot only be studied from a rational perspective on government strategies but need to be studied as political and symbolic interventions. In terms of symbolism, there was much emphasis on corona apps as the 'golden bullet' for dealing with the pandemic. In Asian countries such as South Korea and Singapore, but also in European countries such as Netherlands and Germany, there has been great emphasis on developing an app as a means to manage the spread of 
COVID-19. Evidence about the effectiveness of this app is lacking and the app was strongly contested in many countries. In terms of politics, the analysis highlighted that seemingly rational actions, such as testing for corona or providing public information about the pandemic were highly politicized in many countries. This has been especially the case in countries like the US, UK and Brazil. This highlights that informational responses cannot be understood without an analysis of political dynamics and that to understand technological deployments and decision-making requires a full comprehension of the informational polity.

A third conclusion is that the informational responses encompass much more than developing a corona app. The overview of the six functions shows that governments have implemented a great variety of interventions to strengthen their information management. In public debates in many countries, there has been a strong focus on the pros and cons of developing an app, but the app is actually only one specific intervention. The rich descriptions presented here highlight that we need to broaden our analysis to understand the interlinkages between the various interventions. A key finding, is that governments need to ensure that these various interventions work for all groups in society. Especially those vulnerable groups who do not have access to the informational responses discussed here.

The analysis undertaken for this report was largely descriptive and it is not possible to draw concrete conclusions about the effectiveness of the different approaches adopted. At the same time, on the basis of the extensive literature on information management in the public sector, it is important to highlight the significance of developing a comprehensive approach with a clear focus on public value and the information polity. The conceptual idea of the 'information ecosystem' (Nardi \& O'Day, 1999) can help to highlight and understand the interlinkages between the six functions identified here, and to assess whether these functions combined make a significant contribution to public health policies. In addition, the whole information ecosystem needs to be analyzed in order to assess the legitimacy of the various national responses.

In sum, this exploration of the informational reactions of national governments to the COVID-19 pandemic, on the basis of expert reports, has generated a rich variety of findings and insights. This, however, is only the start of academic research into this subject. More systematic and robust academic research is required to develop a research-based academic understanding of these informational reactions. Two topics can immediately be identified for further future research. The first is a systematic measurement of the informational responses in (all) countries around the world. Our inductive analysis now needs to be followed by deductive research in which the six functions that we identified are systematically measured to enable a thorough comparative analysis. Building upon existing approaches, an analytical instrument should be developed to measure these different functions in a consistent manner. The systematic measurement can be used to analyze relations between informational responses and outcomes in terms of the management of the COVID-19 pandemic. The second topic is an in-depth analysis of the relation between different informational responses and outcomes of the COVID-19 crisis management. Through in-depth studies of patterns over time and through causal process tracing, insights can be generated about the effectiveness and legitimacy of different informational responses in different contextual conditions. Scholars of e-government and the information polity are well placed to further this research agenda and to provide important insight and evidence about the way in which the COVID-19 pandemic has been managed across the world.

\section{References}

Calton, B., Abedini, N., \& Fratkin, M. (2020). Telemedicine in the time of coronavirus. Journal of Pain and Symptom Management, 60(1), e12-e14. 
Harari, Y. (2020). Yuval Noah Harari: the world after coronavirus. Financial Times. 20 March 2020. https://www.ft.com/content/ 19d90308-6858-11ea-a3c9-1fe6fedcca75.

Hollander, J.E., \& Carr, B.G. (2020). Virtually perfect? Telemedicine for COVID-19. New England Journal of Medicine, 382(18), $1679-1681$.

Homburg, V. (2008). Understanding e-government: Information systems in public administration. London: Routledge.

Housel, T.J., El Sawy, O.A., \& Donovan, P.F. (1986). Information systems for crisis management: lessons from southern california edison. Mis Quarterly, 10(4), 389-400.

Ienca, M., \& Vayena, E. (2020). On the responsible use of digital data to tackle the COVID-19 pandemic. Nature Medicine, 26(4), 463-464

Nardi, B.A., O’Day, V., \& O’Day, V.L. (1999). Information Ecologies: Using Technology with Heart. Cambridge MA: MIT Press.

Park, D.A. (2017). A study on conversational public administration service of the Chatbot based on artificial intelligence. Journal of Korea Multimedia Society, 20(8), 1347-1356.

Perry, D.C., Taylor, M., \& Doerfel, M.L. (2003). Internet-based communication in crisis management. Management Communication Quarterly, 17(2), 206-232.

Pueyo, T. (2020). Coronavirus: The Hammer and the Dance. Medium. 19 March 2020. https://medium.com/@ tomaspueyo/ coronavirus-the-hammer-and-the-dance-be9337092b56.

Quarantelli, E.L. (1988). Disaster crisis management: A summary of research findings. Journal of Management Studies, 25(4), 373-385.

Sá, F., Rocha, Á., \& Cota, M.P. (2016). From the quality of traditional services to the quality of local e-Government online services: A literature review. Government Information Quarterly, 33(1), 149-160.

Sweeney, Y. (2020). Tracking the debate on COVID-19 surveillance tools. Nature Machine Intelligence, 2(6), 301-304.

Taylor, J. (1998). Informatization as X-Ray. What is Public Administration for the Information Age. In: Snellen, I.T.M., \& van de Donk, WS.B.H.J., (eds.). Public Administration in an Information Age. A Handbook. Amsterdam: IOS Press, pp. 21-32.

West, D.M. (2005). Digital government: Technology and public sector performance. Princeton: Princeton University Press.

Yuan, Q., \& Gasco-Hernandez, M. (2019, Online First). Open innovation in the public sector: creating public value through civic hackathons. Public Management Review. doi: 10.1080/14719037.2019.1695884. 